\title{
Remote Community Electrification
}

\author{
M. Anyi ${ }^{1}, \mathrm{~S} . \mathrm{Ali}^{2}$ and B.Kirke ${ }^{3}$ \\ ${ }^{1}$ School of Electrical and Information Engineering \\ University of South Australia \\ Mawson lakes Boulevard, Mawson Lakes, South Australia, 5095 Australia. \\ Phone/Fax:+61883023341, +61883023384, e_mail: anymy002@students.unisa.edu.au \\ ${ }^{2}$ School of Electrical and Information Engineering \\ University of South Australia \\ Mawson lakes Boulevard, Mawson Lakes, South Australia, 5095 Australia. \\ Phone/Fax:+61883023346, +61883023384, e_mail: sam.ali@unisa.edu.au \\ ${ }^{3}$ Sustainable Energy Centre \\ University of South Australia \\ Mawson lakes Boulevard, Mawson Lakes, South Australia, 5095 Australia. \\ Phone/Fax:+61883023568, +61883023380, e_mail: brian.kirke@unisa.edu.au
}

\begin{abstract}
Small remote communities often lack basic utilities such as electricity supply for lighting, refrigeration, communications etc. It is usually uneconomic to provide mains power, even when high voltage lines pass by a village. Dieselpowered generators require fuel which is expensive and difficult to bring into remote areas. They are noisy and they require maintenance which is neglected in remote area. Neither wind nor sun provide reliable power in humid tropical regions where there is a lot of still, overcast weather, even when wind turbines or solar panels can be located above the trees. Towers attract lightning strikes which can destroy electronic controls, fungus grows on solar panels, and the multiple electrical connections on photovoltaic arrays corrode away in hot, humid climates.
\end{abstract}

Micro-hydro is an attractive option in mountainous areas, and author 1 has built a $30 \mathrm{kw}$ high head and a $3 \mathrm{kw}$ low head plant, using village labor, surplus and discarded materials. Both are operating satisfactorily. However conventional micro-hydro is not possible in flat country where there is little elevation, and work is now in progress (by the team) to evaluate suitable hydrokinetic turbines on rivers in the humid tropics. Numerous companies around the world are now developing hydrokinetic turbines to harvest tidal and river flows, but a major problem with most designs is clogging by floating debris, which could be worst when used in tropical rivers.

\section{Key words}

Remote community, diesel engine, solar and wind energy, micro hydro, hydrokinetic turbines.

\section{Introduction}

Electricity is an important basic need in everyone's daily life, but extending grid wires hundreds of kilometers through difficult terrains and thick jungle just to serve a small remote village is seen to be impractical in economic terms. In Sarawak Malaysia, there are cases whereby high tension electrical wires from a big hydroelectric plant pass through remote villages but the cost of stepping down the power to serve this "tiny" community proved to be too expensive. Therefore local authorities and non-government organizations (NGOs) resort to temporary measures such as installing small diesel generators and solar panels in some accessible remote villages.

Diesel generators are expensive to operate and to maintain by the low income remote community. Fuel must be transported long distances by river or on roads which often wash out. Solar panels and their electronic components also proved to be too fragile in hot and wet countries. Despite the efforts in remote electrification, the progress and success rates remain low partly because of the harsh nature of remote settlements, limited resources, poor planning, lack of research (in problems and technology used) and negligence.

On the other hand, remote peoples' dependency on rivers as a source of water supply, food and transport results in 
most (if not all) remote villages are being situated in close proximity to rivers, which also could be used to generate electricity to ease life in the jungle. While the high, medium and low head micro hydro are gaining popularity in rural or remote electrification in hilly countries, less research and development works are geared towards generating power from the natural flow of downstream rivers in flat countries where many other remote villages are situated.

Some research works have been carried out to gauge the possibility of using small turbines similar to wind turbines for harnessing energy from natural flow of rivers or straits. It was found that the conventional turbines face problems with floating debris (Swenson 1996 \& Swenson 1999). Drastic changes in water level and frequent flash floods in tropical countries are also seen to be major threats. Therefore research and development (by the team) is now in progress on a dedicated hydrokinetic turbine which is uninterrupted by big or small floating debris such as trees, grass, wild vines, leaves, seaweed, rubbish etc. As a precursor to the water current research, this paper outlines some of the approaches and problems of remote electrification in the state of Sarawak Malaysia and other tropical countries around the world.

\section{Remote Electrification}

Providing electricity for remote communities is deemed necessary in order to improve their socio-economic standard (Balakrisnan 2006). With electricity, people in remote areas can ease their daily chores by using electric cooker, water heater, food processing etc without having to comb the jungle for firewood. The ability to use refrigerators is necessary in order to keep perishable food and medicine due to the fact that remote people are far from the source of supplies and that they have to ration what they have before the next trip to town. Electric lights enable some works to be continued into the night and enable school children to study comfortably under a bright light. Relevant technology such as satellite phone, satellite television and internet can be used so as to allow remote people to access information and to communicate with the rest of the world.

Electricity also enables remote communities to set up village industries in order to ease agriculture product processing and also to earn extra income. Food processing such as rice milling, corn, coffee, cocoa etc. can be done using electrical machines, thus saving a lot of time and energy compared to manual processing. It is no doubt that providing electricity in a sustainable way and the appropriate technology will eventually open opportunities for remote people to improve their socioeconomic standard.

\section{Methods Used and Associated Problems}

\section{A. Diesel generator}

Diesel generator is a commonly used method in remote electrification in Sarawak Malaysia and other developing countries due to its low cost, easy to install and easy to operate. The generator sets are normally supplied by the government through one-off mini rural project funds without any allocation for operation (fuel) and maintenance. This means that the villagers have to work out how to run and maintain their own generator set.

Diesel generators used in remote villages are mostly in the range of 3 to $7.5 \mathrm{~W}$. The China made diesel generators are extremely cheap in Malaysia. A $7.5 \mathrm{KW}$ diesel generator set can be bought at about RM1500.00, equivalent to AUD500.00. It is normally pre-installed on a skid frame ready to be transported and used in remote area. It provides four to six hours of electricity at night, depending on the availability of fuel bought using money contributed by each family in the village. Diesel is normally transported using long hours of expensive motor boats ride or off-road vehicles from a nearby bazaar or town. In the highlands of Sarawak, diesel fuel is being flown via a special airplane called the Sky Van. Unfortunately the recent hike in diesel price has paralyzed the use of diesel generators in some low income remote villages in Sarawak. Others are forced to operate for even shorter hours or alternate days. In a worst case scenario, a $30 \mathrm{KW}$ diesel hungry diesel generator supplied by the local government to a remote village called Long Teran Kanan, in Sarawak has been abandoned due to the drastic increase (more that 100\%) in diesel fuel cost recently.

Besides the high cost of fuel, internal combustion engines exhibit high maintenance cost and have poor reliability (Gutierrez-Vera 2000). Based on experience, a $5 \mathrm{KW}$ single piston China made diesel generator may have an average life span of about only two to four years. Failures are commonly associated with the piston and fuel delivery system (especially the nozzle), partly due to poor quality of fuel and lube oil.

Since both the engine and the AC generator are mounted on the same frame, the vibration from the single piston diesel engine is directly transmitted to the AC generator. This causes the exciter rectifier and armature coils to fail. Oil splash from the nearby engine while in operation is also found to be one of the reasons why the AC generator stops producing power (see figure 1).

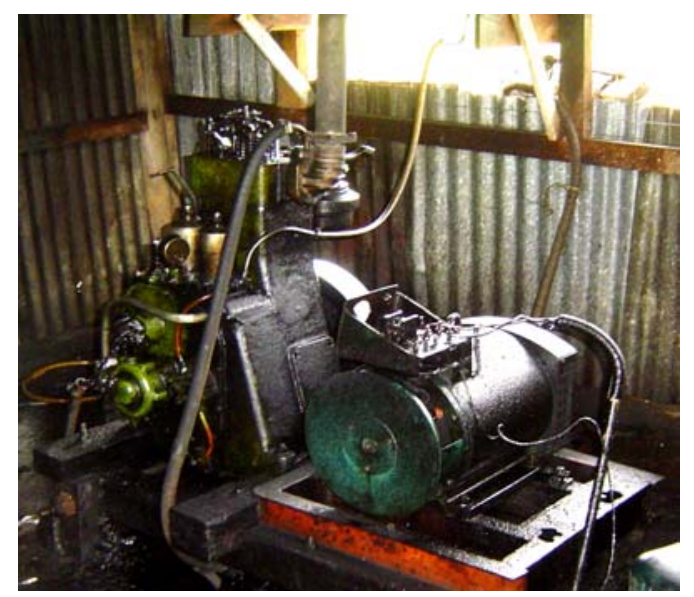

Fig.1: Diesel generator set in a remote village. 
Generally, diesel generators used in remote areas have very little impact on remote communities. Besides for lighting, the limited hours of operation do not allow any significant activity to be carried out in order to improve their socio-economic standard. To a certain degree, the maintenance and operation of a diesel generator is an extra burden for them. Furthermore, the low cost diesel generators are noisy, produce toxic fumes and they require regular maintenance which is often neglected in a less technologically literate society.

\section{B. Solar Energy}

On the ground experience indicates that the life span of solar panels used in hot and wet country is quite short, mainly due to environmental factors and neglect. Because remote people are generally not technically inclined, they are unable to comprehend complicated technology hence the system is not maintained accordingly.

Panels are often installed on a high pole to get clear access to the sunlight but this causes problems when it comes to cleaning. In hot and wet countries, moss and even grass grows on the panels in a short time. Surrounding trees also grow and will shade the panels, thus resulting in poor operation. Figure 2 shows a typical view of solar panels installed in a remote village in the state of Sarawak Malaysia. A rambutan tree has grown over the panels thus preventing them from receiving maximum amount of light. Notice that the whole surface area has turned black due to moss. Some patches of bird dropping are seen on the panels too.

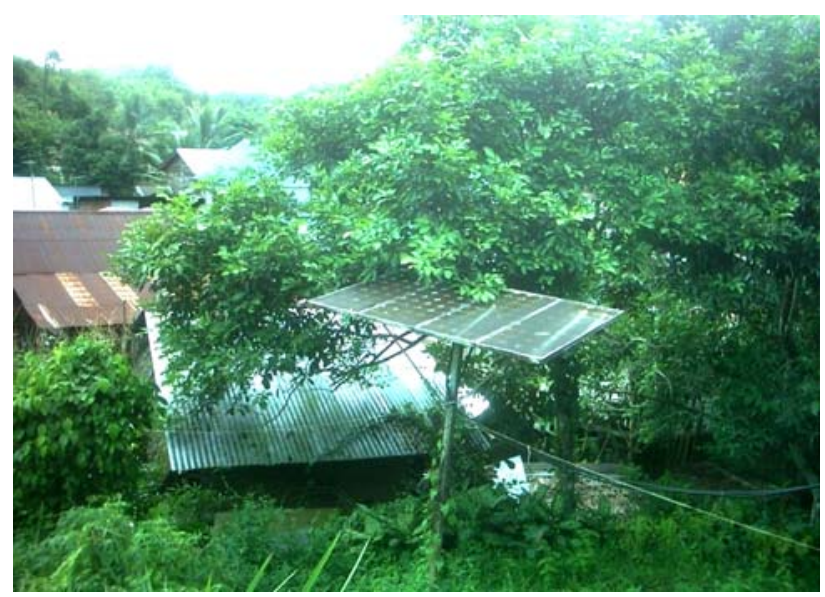

Fig.2: Solar Panels in an equatorial country

Panels mounted on a high pole attract lightning strikes. Some systems ceased operation shortly after installation due to this, destroying electronic components in the inverter cum charge controller. Electrical connections on photovoltaic arrays corrode away and the bypass diodes mounted in the termination box under each panel usually crack due to humidity and heat.

Besides being sensitive to the wet and hot weather, frequent downpours and ever cloudy sky give limited operation hours for the panels to charge batteries. For example, in the highland of Bario Sarawak, heavy rain can last for two days and sometimes no sunny day for three to four days, causing battery banks to run out of charge.

\section{Wind Energy}

Small wind turbines are being used in hybrid with solar panels and diesel generators in some remote nature conservation parks in the coastal area of Sarawak Malaysia. A mechanically self regulated wind turbine shown in Figure 3 was mounted on a metal pole about 30 meters high, surpassing tall trees to gain clear access to the wind. Unfortunately, it was struck by lightning shortly after installation, damaging the electronics that controls the input from both wind turbine and the solar panels. The centre has to bypass the solar energy and the wind energy system and it is now using only the diesel generator.

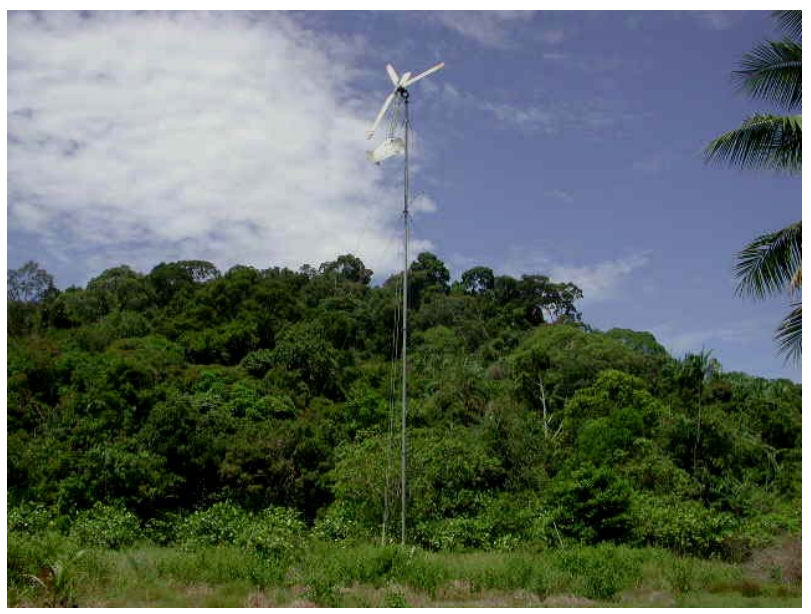

Fig. 3: Small wind turbine on high pole damaged by lightning.

Neither wind nor sun provide reliable power in humid tropical regions where there is a lot of still, overcast weather, even when wind turbines or solar panels can be located above the trees. Huge battery bank is required and a high lighting arrestor must be used to protect the fragile electronics control system. Even then, the wet weather, coupled with the salt breeze from the nearby sea side are very destructive to the massive electronics control used in the hybrid system, the bearings and other rotating parts of the wind turbine and its metal tower

\section{Water power}

As mentioned earlier, most remote communities settled near rivers due to their dependency on rivers for water supply, transportation and food. This makes river power the most potential source of energy for generating electricity.

Micro hydro electric is gaining popularity in many developing countries. Most turbines require a static head of 10 meters and above, although some operate from 3 meters (Freere 1991). This is an attractive option in mountainous country like Nepal, Pakistan, India, Thailand, Peru etc (Balakrisnan 2006, Khenas \& Barnett 
2000). Some remote villages in Malaysia are also situated near to rivers where some significant heads exist, and these could be used to supply free electricity to the low income community there. However conventional microhydro is not possible in flat country where there is little elevation. Therefore research and development work on a rare hydrokinetic turbine operating in natural flow of a river and uninterrupted by small or big floating debris is in progress at University of South Australia

Interest has increased in the area of renewable energy in search for alternative fuel due to the drastic increase of mineral fuel recently. Aimed to eliminate dependency on diesel fuel for electricity generation in remote areas, two experimental micro hydros have been built in two remote villages in Sarawak Malaysia

The first one was a $30 \mathrm{KW}$ micro hydro utilizing a 24 meter head was built using surplus, discarded materials and village labour in 2007 in a remote village called Abok Mawang in Sarawak Malaysia. A small dam was made using precast used U-shape concrete drain sections and water is channelled to the turbine using a pipe system made up of some $450 \mathrm{~mm}$ surplus metal pipes and 300 mm HDPE pipes total up to 140 meters long. The cups of the Pelton like turbine were made using galvanized pipe sections and bolted onto an old bandsaw wheel having a diameter of about 0.6 meter. The turbine and a 24 inch diameter pulley were fitted to a common shaft about 3 inches in diameter. Water jets from two 2.5 inch nozzles turn the turbine at about $250 \mathrm{rpm}$ and mechanical power take-off is taken from a 24 inch diameter pulley via four V-belts to a 4 inch diameter pulley mounted on the shaft of the $30 \mathrm{~kW}$ generator, turning it at about $1500 \mathrm{rpm}$ (loaded). Figure 4 shows the arrangement of turbine runner and power take off of the homemade turbine generator.

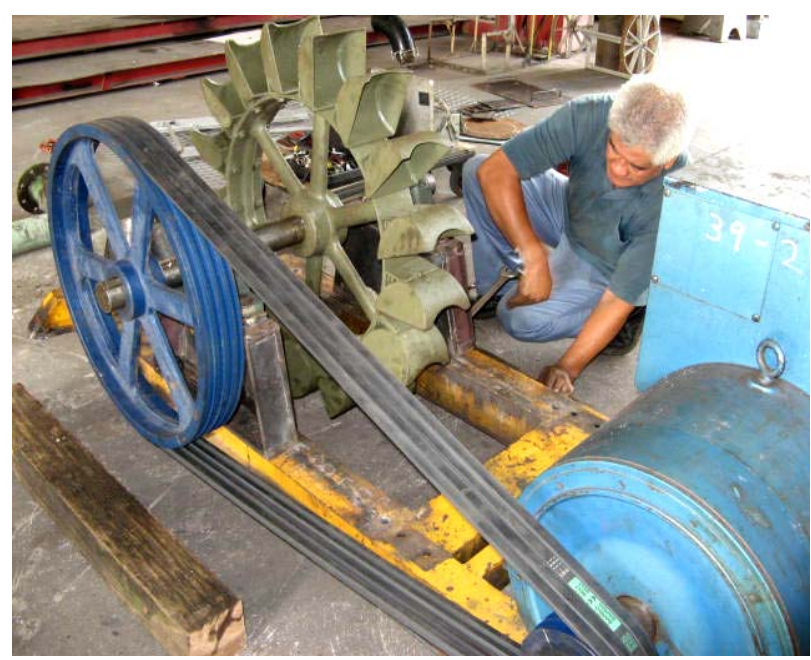

Fig. 4: $30 \mathrm{~kW}$ homemade turbine generator

Power produced by the AC generator is controlled by a simple triac cum dummy load circuits and then transmitted 600 meters to the village via a pair of $30 \mathrm{~mm}^{2}$ aluminium wires. Since the 15 -family village is utilizing only $2.8 \mathrm{KW}$ during peak hours, the donated $30 \mathrm{KW}$ AC generator was replaced with a $7.5 \mathrm{KW}$ generator bought for RM 600.00 (AUD200.00) as shown in Figure 5. The smaller generator uses less water and therefore keeping more water flowing in the river especially in the dry season.

The system works satisfactorily, with minor maintenance work such as replacing the carbon brushes of the synchronous generator every six months and replacing the bolts that hold the turbine cups to the bandsaw wheel. Greasing of the pillow blocks (bearings) that hold the turbine shaft can be greased once a week even while the turbine is in operation. The village now enjoys 24 hours electricity supply enabling them to use electric rice cooker, heater, refrigerator, satellite TV and phone, iron, radio and etc. The good news was soon heard by some members who have left the village and are know seen to come back to enjoy the change. Since the micro hydro started its operation in May 2007, there is s no single cent spent on diesel fuel for electric generation in this village.

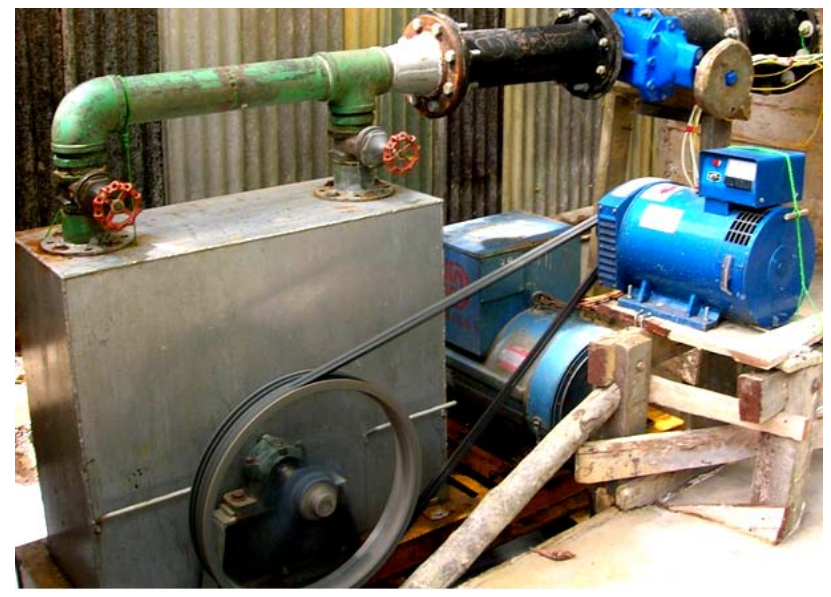

Fig. 5: Final setup of the $30 \mathrm{~kW}$ turbine generator.

As the news about the success of the water powered generator spread, many nearby villages were also interested to adopt the idea. As a result, a second micro hydro was built in the same year but this time utilizing a very limited head of about 5 feet created from a man made lake. After evaluating the site, an overshot waterwheel was built as shown in Figure 6.

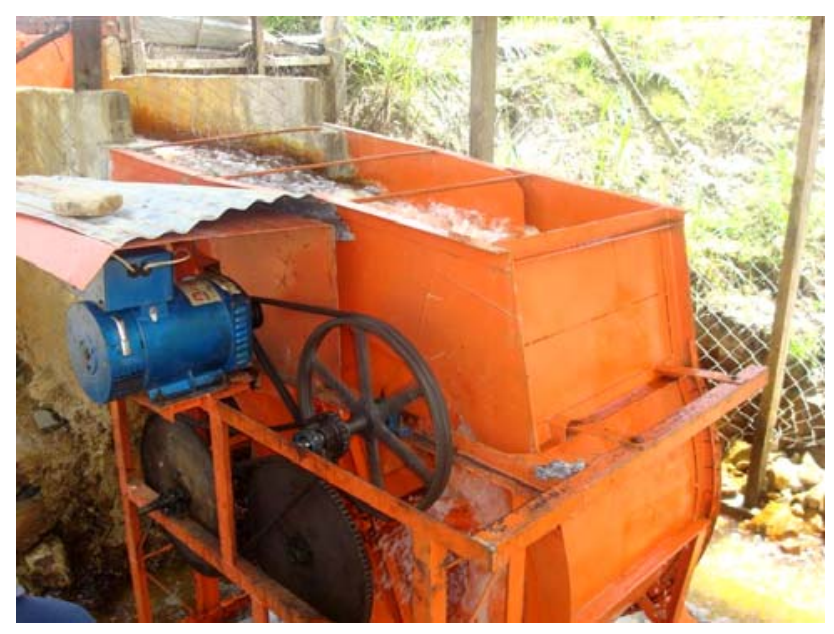

Fig. 6: A $3 \mathrm{~kW}$ overshot waterwheel 
Because of the limited head, the all metal 4 feet diameter and 2.5 feet wide waterwheel had to be fitted with a water guard in order to force maximum amount of water to push the blades of the wheel. The wheel turns about 8 to $10 \mathrm{rpm}$ (with load) therefore multiple sets of sprockets and chains were used to step up the rpm to about 1500 rpm in order to run a $3 \mathrm{KW}$ generator. Power generated from the AC generator is transmitted to a single house about 200 meters away via a pair of $16 \mathrm{~mm}^{2}$ aluminium wires. Because the system supplies a single owner, the voltage is regulated manually at around $200-250$ volts using a conventional light dimmer and two 500W spot lights as dummy load.

As compared to the high head micro hydro, the waterwheel requires more water to run. Water gate is used to regulate and to cut water supply to the wheel. When necessary, it is closed to allow more water to accumulate in the lake so it could be used at full power when needed. Regular greasing of the chain and sprockets is needed in order to reduce friction and rust but the system could be simplified by using a helical speed reducer in reverse (as a speed increaser). This should reduce maintenance work on the sprocket and chains. Nevertheless, the system works satisfactorily in providing long hours of free electricity for a retired teaching couple in a remote home.

\section{Conclusion}

Due to the fact that most remote communities are situated near to rivers, water power should be considered for electricity generation in remote areas. This is especially very practical in tropical countries where rivers flow all year round. Solar and wind energy systems should be installed only after careful consideration because the hot and wet climate is very destructive to electronics used in solar power. Lightning is also a serious threat to both wind and solar energy systems because of the high pole where they are mounted.

Micro hydro proved to be more practical in wet countries. This was demonstrated by the installation of two experimental micro hydros built in remote villages of Sarawak Malaysia. The installations have successfully eliminated dependency on difficult to get and expensive diesel fuel for electricity generation. Never the less, the application of a micro hydro requires a significant head,. Therefore a dedicated research and development on a practical and debris resistant hydro kinetic turbine is now underway in order to tap energy from the natural flow of rivers or tidal current in straits for the benefit of remote people who live in flat areas.

\section{References}

[1.] Balakrisnan, B., "Women and Micro-hydro Systems”, Himalayan Small Hydropower Summit New Delhi, 2006.
[2.] Gutierrez-Vera, J., "Renewables for Sustainable Village Power Supply”, IEEE. Power Engineering Society Winter Meeting Singapore, 2000.

[3.] Freere, P., "Electronic Load/Excitation for a Selfexcited Squirrel Cage Generator Micro-hydro", IEEE Fifth International Conference on Electrical Machines and Drives, Conf. Publ. No. 341, 1991

[4.] Khenas, S., and Barnett, A., "Best practices for sustainable development of micro hydro power in developing countries”, A report for Department for International, Development, UK and the World Bank, March 2000.

[5.] Swenson, W. J. “ The Evaluation of an Axial Flow, Lift Type Turbine for Harnessing The Kinetic Energy in Tidal Flow", Australian Universities Power Engineering Conference AUPEC, Darwin, Australia, Sept. 26-29, 1999.

[6.] Swenson, W.J., "The Specification, Design and Development of a Kinetic Energy Tidal Power Generator," Engineering Tomorrow Today, the Darwin Summit, National Engineering Conference, Australia. 1996. 